\title{
Comparison of Subjective and Objective Success of Septoplasty in Patients with Nasal Septum Deviation: A Before and After Study
}

\author{
Aytekin Uzer ${ }^{1,3}$ (D) Erhan Demirhan ${ }^{2,3}$ (D) \\ ${ }^{1}$ Dr. Aytekin Uzer's Special Clinic, Istanbul, Turkey \\ ${ }^{2}$ VoicENT - ENT \& Voice Disorder Center, Izmir, Turkey \\ ${ }^{3}$ Health Sciences University Tepecik Training and Research Hospital Ear Nose Throat Diseases and Head \& Neck Surgery Clinic, Izmir, Turkey
}

ORCID ID: A.U. 0000-0002-4342-6066; E.D. 0000-0001-8871-0821

Citation: Uzer A, Demirhan E. Comparison of subjective and objective success of septoplasty in patients with nasal septum deviation: a before and after study. Tr-ENT 2021;31(2):25-33. https://doi.org/10.26650/Tr-ENT.2021.40412

\begin{abstract}
Objective: Aim of the study is to evaluate the subjective outcomes and objective outcomes postoperatively and investigate correlations between these measurements.

Material and Methods: This prospective before and after surgical study was conducted with patients admitted with symptomatic nasal septum deviation (NSD) and who underwent Cottle's septoplasty. Morphometric diameters of the nasal cavity were measured using a multi-detector computed tomography. Preoperative and postoperative one-month Nasal Obstruction Symptom Evaluation Scale (NOSE) Score, acoustic rhinometry (AR), and anterior active rhinomanometry (AAR) measurements were used to evaluate the success of surgery. The correlations between these measurements were also evaluated.

Results: The study population consisted of 30 patients, including 19 males and 11 females, with a median age of 27.5 years. There was a statistically significant difference between pre and postoperative NOSE scores, with a mean difference of 53.17 points $(p<0.001)$. There were statistically significant differences between pre and postoperative AR parameters of both the deviated side (DS) and non-deviated side (NDS) of the nose both before and after decongestion. There were statistically significant improvements in all postoperative airflow and airway resistance parameters of the DS of the nose before decongestion when compared to preoperative measurements. There were moderate to large positive correlations between morphometric diameters and differences in NOSE score. Further, there were several statistically significant correlations between differences in AR and AAR measurements and differences in NOSE score.

Conclusion: Our findings showed that the objective measurements are strongly correlated with the NOSE score.
\end{abstract}

Keywords: Pyriform aperture, choana, nasal septum deviation, septoplasty

\section{INTRODUCTION}

Nasal obstruction is one of the most common complaints in the rhinology clinical practice $(1,2)$. Although conservative nonsurgical medical therapy is the first option for the treatment of nasal obstruction, it is usually unsuccessful in relieving complaints of nasal obstruction which resulted from a deviated or deformed nasal septum (3). Septoplasty is widely performed to correct the septal deviation or deformity, and therefore is one of the most commonly performed surgical procedures in otorhinolaryngology (4-6).
Septoplasty is the surgical correction of the deviated or deformed nasal septum, the first examples of which date back to ancient Egypt (7). Nowadays, a variety of techniques are performed by surgeons in septoplasty operations; the types of nasal septal deviation (NSD) and surgeon's preferences are important to decide which technique to be applied $(8,9)$. Cottle's septoplasty with a hemitransfixion incision is one of the most frequently used techniques in the world (9).

In clinical practice, there are several diagnostic tools including subjective and objective measurements (10). Subjective

Corresponding Author: Aytekin Uzer E-mail: aytekinuzer@gmail.com

Submitted: 31.03.2021 • Accepted: 02.06.2021 
measurements use validated questionnaires and try to determine the level of the patient's discomfort before surgery and also the relief of the patient's symptoms after surgery (2). Although subjective measurements have been used widely in clinical practice, their subjective nature is an ongoing problem, especially in long-term follow-up assessments $(11,12)$.

Objective measurements use several analysis methods, examine the deformed anatomy of the nose, measure the degree of nasal obstruction and evaluate nasal resistance (10). These methods provide detailed objective measurements before the surgery and guide the surgeons to decide the most convenient surgical technique (2). They are also repeated after surgery to show the effectiveness of the applied surgery, such as the correction of an anatomical part or obtaining openness (lack of obstruction) of a bodily passage (6). However, several studies have demonstrated that favorable postoperative measurements did not result in the patient's satisfaction (10). Therefore, there is a long and still ongoing conflict in the reliability of objective measurements of nasal patency and patient satisfaction (2).

This study aims to compare subjective outcomes such as the Nasal Obstruction Symptom Evaluation Scale (NOSE) score and objective outcomes such as acoustic rhinometry (AR) and anterior active rhinomanometry (AAR) measurements of Cottle's septoplasty in patients with NSD, and to evaluate the correlations between morphometric measurements and the difference in those subjective and objective outcomes.

\section{MATERIAL AND METHODS}

\section{Design and setting}

This prospective before and after surgical study was conducted with patients admitted with symptomatic nasal septum deviation (NSD) and underwent septoplasty in the University of Health Sciences Izmir Tepecik Training and Research Hospital between October 2016 and November 2016. Ethical approval was obtained from Izmir Tepecik Training and Research Hospital Ethics Committee (Approval date:18/08/2016, No:22), and written informed consent was obtained from all patients included in the study after detailed information about the study was given.

\section{Patients}

Patients between the ages of $18-45$ who presented complaints of nasal obstruction, difficulty in breathing through the nose and were diagnosed with NSD after physical examination, paranasal endoscopy, and paranasal computed tomography, were evaluated for eligibility. The patients with additional nasal or paranasal pathology, history of previous nasal or paranasal surgery, craniofacial anomaly, sinonasal malignancy, adenoid hypertrophy, nasal valve collapse, additional lower and upper respiratory pathology, cardiovascular or neurological pathology were excluded from the study.

\section{Surgical procedure}

All patients underwent Cottle's septoplasty by a 3-years experienced surgeon under general or local anesthesia. A hemitransfixion incision was performed, and the deviated septal portion was excised after elevating the mucoperichondrium and mucoperiosteum. After surgery, a nasal packing was applied and removed on the second postoperative day. All patients were prescribed postoperative antibiotics, analgesics, and decongestants. Patients were followed-up with outpatient visits at the postoperative first and second week and first month.

\section{Variables and outcomes}

Patients' demographics and clinical features were recorded. The type of NSD was classified according to the Mladina classification using nasal endoscopic evaluation (Karl Storz Image 1 HUB HD camera system H3-Z Head, Germany) of the patients (13).

A multi-detector computed tomography (MDCT) (Siemens SOMATOM Definition AS 128 Slice CT scan, Germany) was used to exclude paranasal sinus pathologies preoperatively and to do morphometric measurements. The morphometric diameters were measured in millimeters $(\mathrm{mm})$ based on a Turkish anatomic study by Aksu et al. (14). The morphometric variables were: (1) piriform aperture height, (PAH) which was defined as the distance between the rhinion and the anterior nasal spine; (2) piriform aperture width, (PAW) which was defined as the widest distance between the left and right bone margin on the transverse plane of pyriform aperture; (3) upper anterior face height, (UAFH) which was defined as the distance between nasion and anterior nasal spine; (4) choana height, $(\mathrm{CH})$ which was defined as the distance between the furthest points on the vertical midline; (5) choana width, (CW) which was defined as the distance between the furthest points on the horizontal midline; (6) airway length, $(A L)$ which was defined as the distance between the anterior nasal spine and the posterior nasal spine; and (7) upper palate width, (UPW) which was defined as the distance between the junction of the juga alveolaria of the first and second molar teeth (Figure 1).

There are three primary outcomes of the study. These are the Nasal Obstruction Symptom Evaluation Scale (NOSE) score, acoustic rhinometry (AR) measurements, and anterior active rhinomanometry (AAR) measurements. Preoperative and postoperative one-month measurements were compared to evaluate the success of the surgery. Also, the correlation between the morphometric measurements, the differences (as an effect size) in AR and AAR parameters between pre and postoperative measurements, and the difference between pre and postoperative NOSE scores were evaluated.

AR (Rhinoscan ${ }^{\circledR}$ V2.6) and AAR (Rhinostream ${ }^{\circledR}$ V2.1) measurements were performed using the SRE 2000 Rhinometer before and one month after surgery, (RhinoMetrics, Lynge, Denmark) following the recommendations of the International Rhinology Society and the European Rhinology Society in 2000 and $2005(15,16)$. The measurements were made on both the deviated side (DS) and non-deviated side (NDS) of the nose before nasal decongestion (BD) and after nasal decongestion (AD). AD parameters were measured 30 minutes after applying $0.01 \%$ xylometazoline HCL to both nostrils. 


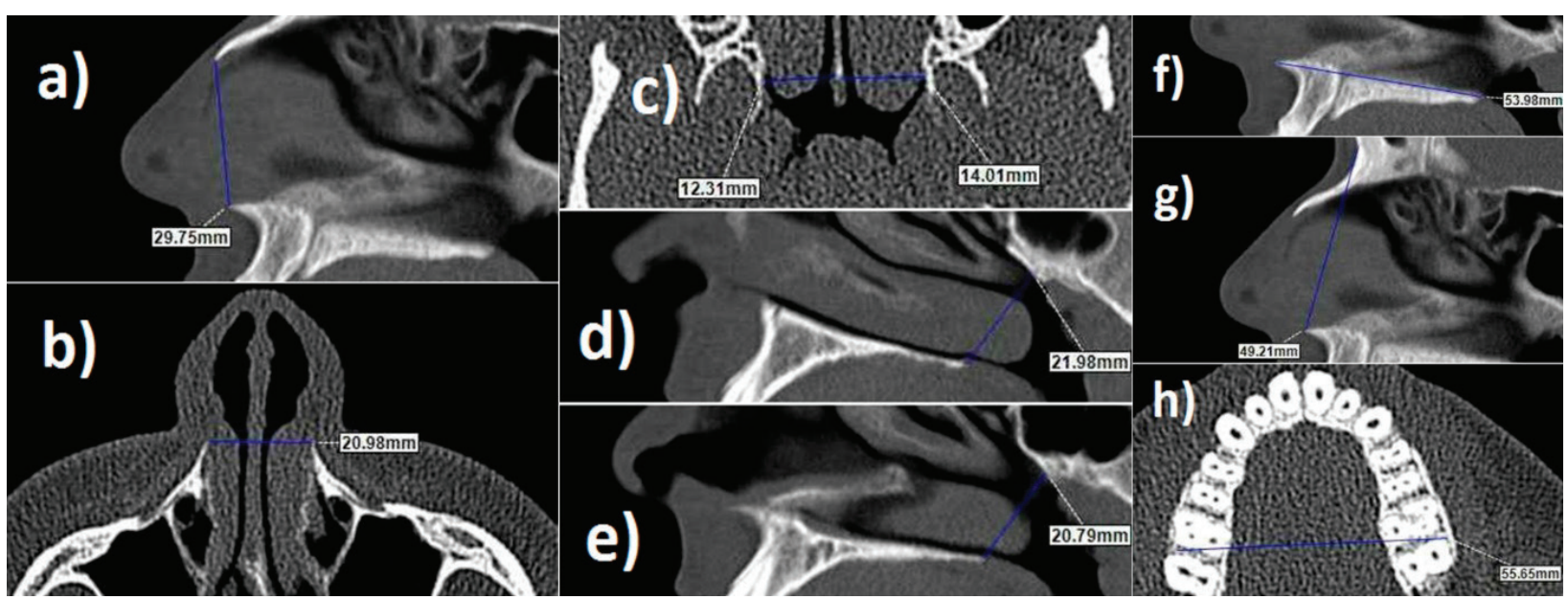

Figure 1 shows the morphometric measurements of a patient with right-sided nasal septal deviation.

a) piriform aperture height of $29.75 \mathrm{~mm}, \mathrm{~b}$ ) piriform aperture width of $20.98 \mathrm{~mm}, \mathrm{c}$ ) deviated side choana width of $12.31 \mathrm{~mm}$ and non-deviated side choana width of $14.01 \mathrm{~mm}, \mathrm{~d}$ ) non-deviated choana height of $21.98 \mathrm{~mm}$, e) deviated side choana height of $20.79 \mathrm{~mm}, \mathrm{f}$ ) airway length of $53.98 \mathrm{~mm}, \mathrm{~g}$ ) upper anterior face height of $49.21 \mathrm{~mm}$, and h) upper palate width of $55.65 \mathrm{~mm}$.

The variables of the AR were: (1) the first minimal crosssectional area (MCA1), which was the narrowest cross-sectional area $\left(\mathrm{cm}^{2}\right)$ at a distance of $0-2.2 \mathrm{~cm}$ from the nostril; (2) the second minimal cross-sectional area 2 (MCA2), which was the narrowest cross-sectional area $\left(\mathrm{cm}^{2}\right)$ at a distance of 2.2-5.4 $\mathrm{cm}$ from the nostril (3) the first volume (Vol1) of one side of the nasal cavity, which was the unilateral volume $\left(\mathrm{cm}^{3}\right)$ of the nasal cavity between the nostril and $2.2 \mathrm{~cm}$ into the cavity; (4) the second volume (Vol2) of one side of the nasal cavity, which was the unilateral volume $\left(\mathrm{cm}^{3}\right)$ of the nasal cavity between 2.2 to $5.4 \mathrm{~cm}$ from the nostril; (5) total volume of one side of the nasal cavity (tVol), which was the sum of Vol1 and Vol2; and (6) Total volume of two sides of the nasal cavity (TVol).

The AAR parameters were: (1) inspiration airflow of one side of the nasal cavity $\left(\mathrm{Flow}_{\text {ins }}\right)$; (2) expiration airflow of one side of the nasal cavity (Flow ${ }_{\text {ex }}$ ); (3) total airflow of one side of the nasal cavity (tFlow) which was the sum of Flow ${ }_{\text {ins }}$ and Flow ${ }_{\text {ex; }}$ (4) Total airflow of two sides of the nasal cavity (TFlow); (5) inspiration airway resistance of one side of the nasal cavity $\left(A R_{\text {ins }}\right) ;(6)$ expiration airway resistance of one side of the nasal cavity $\left(A R_{\text {ex }}\right)$; (7) total airway resistance of one side of the nasal cavity (tAR) which was the sum of $A R_{\text {ins }}$ and $A R_{\text {ex;and }}$ (8) Total airway resistance of two sides of the nasal cavity (TAR).

\section{Statistical analysis}

Statistical analysis was performed using SPSS 22.0 (IBM Corporation, Armonk, New York, United States). Descriptive statistics were presented as median with interquartile range (IQR) for non-normal distributed numeric variables, and frequency $(n)$ with percentage (\%) for categorical variables. The descriptive statistics of pre and postoperative numerical measurements and the differences between those two measurements were presented as mean with $95 \%$ confidence interval $(95 \% \mathrm{Cl})$. A Related-Samples Wilcoxon Signed Rank Test was used for comparing pre and postoperative numerical measurements. The Spearman's Rank Order Correlation was used for evaluating the correlation between anatomical measurements, differences in functional measurements, and differences in NOSE scores before and after surgery. A $p$-value less than 0.05 was considered as the statistically significant level.

\section{RESULTS}

Although 37 patients were enrolled in the study, 7 patients were excluded from the study due to the development of septal perforation in 2 patients, nasal synechia in 1 patient, inadequacy of the surgery in 1 patient, inappropriate MDCT images in 1 patient, and 2 patients not coming for a control visit during the follow-up period. Finally, the study population consisted of 30 patients, including 19 males and 11 females, with a median age of 27.5 years. Of the patients, 21 (70.0\%) had right-sided deviation and 9 had left-sided deviation, and most of the patients (60.0\%) were classified as type 7 according to the Mladina classification. The second most common type was type 2 with a percentage of 16.7. The median PAH was $33.94 \mathrm{~mm}$, the median PAW was $21.25 \mathrm{~mm}$, the median UAFH was $53.25 \mathrm{~mm}$, the median $\mathrm{CH}$ of the deviated side of the nose $23.62 \mathrm{~mm}$, the median $\mathrm{CH}$ of the non-deviated side of the nose was $23.33 \mathrm{~mm}$, the median $\mathrm{CW}$ of the deviated side of the nose was $13.66 \mathrm{~mm}$, the median CW of the non-deviated side of the nose was $13.60 \mathrm{~mm}$, the median AL was $53.39 \mathrm{~mm}$, and the median UPW was $55.57 \mathrm{~mm}$ (Table 1).

Table 2 presents the comparison of the pre and postoperative NOSE scale scores of the patients. There was a statistically significant difference between pre and postoperative NOSE scores with a mean difference of 53.17 points $(p<0.001)$.

Table 3 shows the comparison of the pre and postoperative acoustic rhinometry parameters of the patients. Except for the MCA2 measurements of the non-deviated side of the nose 
Table 1: Demographics, clinical features and nasal morphometric measurements of the patients

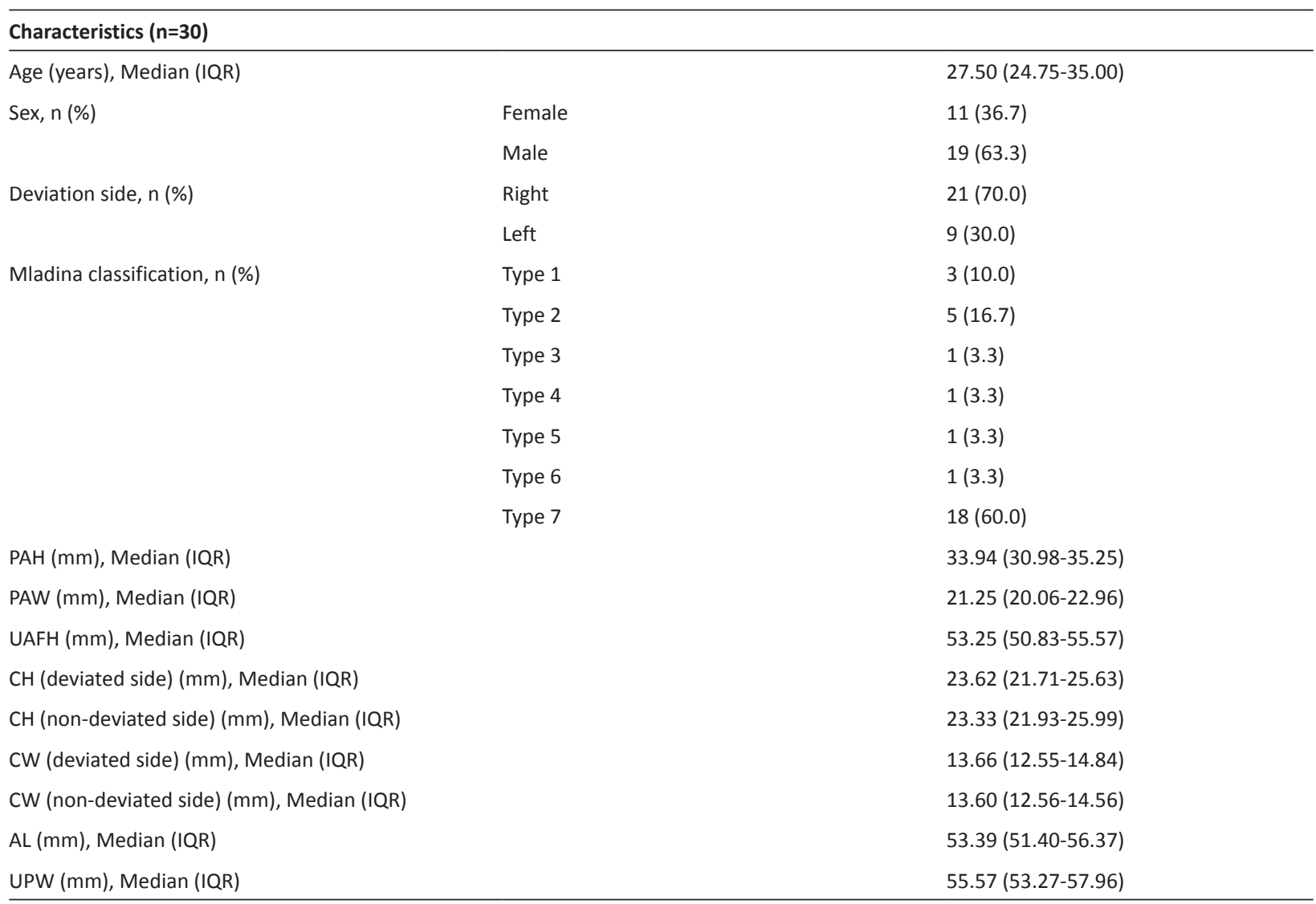

Note: IQR: Interquartile range; PAH: Height of the piriform aperture, PAW: Width of the piriform aperture; UAFH: Upper anterior face height; $\mathrm{CH}$ : Choana height; CW: Choana width; AL: Airway length; UPW: Upper palate width.

Table 2: Comparison of the pre and postoperative NOSE scale scores of the patients

\begin{tabular}{lccc}
\hline & $\begin{array}{c}\text { Preoperative, } \\
\text { mean (95\% Cl) }\end{array}$ & $\begin{array}{l}\text { Postoperative, } \\
\text { mean (95\% Cl) }\end{array}$ & $\begin{array}{c}\text { Difference, } \\
\text { mean (95\% Cl) }\end{array}$ \\
\hline NOSE Score & $60.50(53.71-67.30)$ & $7.33(4.04-10.62)$ & $-53.17(-59.68--46.66)$ \\
\hline
\end{tabular}

*Related-Samples Wilcoxon Signed Rank Test was used.

both before and after decongestion, there were statistically significant differences between all pre and postoperative acoustic rhinometry parameters of deviated and non-deviated sides of the nose both before and after decongestion.

Table 4 presents the comparison of the pre and postoperative rhinomanometry parameters of the patients. There were statistically significant improvements in all postoperative airflow and airway resistance parameters of the deviated side of the nose before decongestion when compared to preoperative measurements. Also, there was a statistically significant difference between pre and postoperative inspiration airway resistance of the deviated side of the nose after decongestion.

Table 5 shows the statistically significant correlations between anatomical measurements, differences in functional measurements, and differences in NOSE scores of the patients.
There were moderate positive correlations between the CW of the deviated side of the nose, UPW, and difference in NOSE score (R:0.429, p:0.018 and R:0.397, p:0.030). Similarly, there was a large positive correlation between the $\mathrm{CW}$ of the non-deviated side of the nose and the difference in NOSE scores (R:0.514, p:0.004). There were statistically significant moderate positive correlations between differences in acoustic rhinometry measurements such as Vol1 of the deviated side of the nose before decongestion, Vol2 of the non-deviated side of the nose before deviation, tVol1 of the non-deviated side of the nose before decongestion, TVol1 before decongestion, and difference in NOSE score.

The difference in flow parameters of the rhinomanometry of the deviated side of the nose which showed moderate negative correlations with difference in NOSE scores were Flowins, Flowex, and tFlow after decongestion. However, the 
Table 3: Comparison of the pre and postoperative acoustic rhinometry parameters of the patients

\begin{tabular}{|c|c|c|c|c|c|c|}
\hline Parameter & Side & Decongestion & $\begin{array}{l}\text { Preoperative, } \\
\text { mean }(95 \% \mathrm{Cl})\end{array}$ & $\begin{array}{l}\text { Postoperative, } \\
\text { mean }(95 \% \mathrm{Cl})\end{array}$ & $\begin{array}{l}\text { Difference, } \\
\text { mean }(95 \% \mathrm{Cl})\end{array}$ & $p^{*}$ \\
\hline \multirow{4}{*}{ MCA1 $\left(\mathrm{cm}^{2}\right)$} & \multirow{2}{*}{ Deviated } & Before & $0.443(0.383-0.502)$ & $0.569(0.522-0.616)$ & $0.127(0.091-0.162)$ & $<0.001$ \\
\hline & & After & $0.487(0.434-0.540)$ & $0.605(0.561-0.650)$ & $0.118(0.077-0.159)$ & $<0.001$ \\
\hline & \multirow{2}{*}{ Non-deviated } & Before & $0.587(0.544-0.630)$ & $0.679(0.643-0.715)$ & $0.092(0.049-0.135)$ & $<0.001$ \\
\hline & & After & $0.598(0.558-0.638)$ & $0.684(0.651-0.717)$ & $0.087(0.057-0.116)$ & $<0.001$ \\
\hline \multirow{4}{*}{$\operatorname{MCA2}\left(\mathrm{cm}^{2}\right)$} & \multirow{2}{*}{ Deviated } & Before & $0.495(0.393-0.598)$ & $0.580(0.500-0.661)$ & $0.085(0.014-0.156)$ & 0.006 \\
\hline & & After & $0.502(0.432-0.571)$ & $0.636(0.556-0.716)$ & $0.134(0.071-0.197)$ & $<0.001$ \\
\hline & \multirow{2}{*}{ Non-deviated } & Before & $0.783(0.712-0.854)$ & $0.838(0.751-0.925)$ & $0.055(-0.023-0.133)$ & 0.198 \\
\hline & & After & $0.853(0.760-0.947)$ & $0.940(0.845-1.036)$ & $0.087(-0.018-0.192)$ & 0.245 \\
\hline \multirow{4}{*}{ Vol1 $\left(\mathrm{cm}^{3}\right)$} & \multirow{2}{*}{ Deviated } & Before & $1.810(1.666-1.953)$ & $1.987(1.852-2.122)$ & $0.177(0.058-0.297)$ & 0.001 \\
\hline & & After & $1.766(1.651-1.881)$ & $2.007(1.880-2.135)$ & $0.241(0.162-0.320)$ & $<0.001$ \\
\hline & \multirow{2}{*}{ Non-deviated } & Before & $1.792(1.676-1.908)$ & $2.061(1.948-2.175)$ & $0.269(0.192-0.346)$ & $<0.001$ \\
\hline & & After & 1.785 (1.659-1.911) & $2.070(1.961-2.179)$ & $0.285(0.211-0.358)$ & $<0.001$ \\
\hline \multirow{4}{*}{ Vol2 $\left(\mathrm{cm}^{3}\right)$} & \multirow{2}{*}{ Deviated } & Before & $4.513(3.460-5.566)$ & 6.405 (5.667-7.143) & $1.892(1.102-2.681)$ & $<0.001$ \\
\hline & & After & $5.265(4.392-6.137)$ & $7.600(6.796-8.404)$ & $2.335(1.441-3.230)$ & $<0.001$ \\
\hline & \multirow{2}{*}{ Non-deviated } & Before & $5.570(4.638-6.502)$ & $6.677(6.017-7.337)$ & $1.107(0.204-2.010)$ & 0.002 \\
\hline & & After & 6.905 (5.915-7.895) & $8.014(7.331-8.697)$ & $1.110(0.264-1.955)$ & 0.024 \\
\hline \multirow{4}{*}{$\mathrm{tVol}\left(\mathrm{cm}^{3}\right)$} & \multirow{2}{*}{ Deviated } & Before & $6.323(5.203-7.442)$ & $8.392(7.636-9.147)$ & $2.069(1.266-2.872)$ & $<0.001$ \\
\hline & & After & 7.031 (6.123-7.939) & $9.607(8.781-10.434)$ & $2.577(1.675-3.478)$ & $<0.001$ \\
\hline & \multirow{2}{*}{ Non-deviated } & Before & $7.362(6.404-8.320)$ & 8.738 (8.091-9.385) & $1.377(0.458-2.296)$ & 0.001 \\
\hline & & After & 8.690 (7.683-9.696) & $10.084(9.399-10.769)$ & $1.394(0.515-2.273)$ & 0.010 \\
\hline \multirow{2}{*}{ TVol $\left(\mathrm{cm}^{3}\right)$} & & Before & $13.684(12.085-15.283)$ & $17.130(15.984-18.276)$ & $3.446(2.224-4.667)$ & $<0.001$ \\
\hline & & After & $15.720(14.204-17.237)$ & $19.691(18.356-21.027)$ & $3.971(2.726-5.216)$ & $<0.001$ \\
\hline
\end{tabular}

Note: MCA1: Minimal cross-sectional area 1 of one side of nasal cavity; MCA2: Minimal cross-sectional area 2 of one side of nasal cavity; Vol1: Volume 1 of one side of nasal cavity; Vol2: Volume 2 of one side of nasal cavity; tVol: Total volume of one side of nasal cavity; TVol: Total volume of two sides of nasal cavity.

* Related-Samples Wilcoxon Signed Rank Test was used.

difference in flow parameters of the rhinomanometry of the non-deviated side of the nose which showed moderate positive correlations with the difference in NOSE scores were Flowex, and tFlow after decongestion. Additionally, the difference in airway resistance parameters of the deviated side of the nose which had moderate positive correlations with the difference in NOSE scores were ARins after decongestion, ARex before decongestion, ARex after decongestion, and tAR before decongestion.

\section{DISCUSSION}

The major expectancy of patients who have a septoplasty operation due to nasal septum deviation is to have more comfortable nasal breathing $(5,17)$. However, the main postoperative outcome is the satisfaction and improvement of the quality of life of the patient. The effectiveness of the performed surgery is evaluated by the patients and can be accepted as a success if their preoperative symptoms related to nasal septum deviation are completely improved and they feel an apparent increase in life quality (6). Therefore, the patient's feelings and welfare evaluated by the subjective measurements provide a more meaningful picture of the effectiveness of the applied surgery than the objective methods (17). However, the subjective nature of these methods is a challenge, especially in repeated measures. Follow-up measures are performed by the surgeons to show the ongoing effectiveness of the performed surgery at 3, 6, or 12 months after septoplasty. Therefore, lots of investigators use objective measurements besides the subjective ones, and also investigate their correlations $(5,18)$.

In the literature, lots of studies have used symptom score questionnaires such as the NOSE score, which is one of the most widely used. These questionnaires provide valuable information about the severity of nasal obstruction from a patient's point of view, and also about the degree of postoperative satisfaction $(5,19)$. Eren et al. reported a significant decrease in the NOSE score of patients with nasal obstruction after septoplasty (20). Mondina et al. stated that all NOSE scores of patients with nasal obstruction decreased significantly after an applied septoplasty operation (10). Lodder et al. reported that the mean preoperative and postoperative NOSE score was 78.4 and 23.0, respectively, and the mean improvement was 55.4 (21). We found similar results in the literature that the mean 
Table 4: Comparison of the pre and postoperative rhinomanometry parameters of the patients

\begin{tabular}{|c|c|c|c|c|c|c|}
\hline Parameter & Side & Decongestion & $\begin{array}{l}\text { Preoperative, } \\
\text { mean }(95 \% \mathrm{Cl})\end{array}$ & $\begin{array}{l}\text { Postoperative, } \\
\text { mean }(95 \% \mathrm{CI})\end{array}$ & $\begin{array}{l}\text { Difference, } \\
\text { mean }(95 \% \mathrm{Cl})\end{array}$ & $p^{*}$ \\
\hline \multirow{4}{*}{ Flow $_{\text {ins }}\left(\mathrm{cm}^{3} / \mathrm{s}\right)$} & \multirow{2}{*}{ Deviated } & Before & $269.70(238.35-301.06)$ & $344.93(329.98-359.89)$ & $75.23(41.60-108.87)$ & $<0.001$ \\
\hline & & After & 318.67 (297.40-339.93) & $340.63(331.53-349.74)$ & $21.97(-1.49-45.43)$ & 0.052 \\
\hline & \multirow{2}{*}{ Non-deviated } & Before & $329.43(321.66-337.20)$ & $348.23(324.05-372.42)$ & $18.80(-9.32-46.92)$ & 0.616 \\
\hline & & After & 364.33 (330.68-397.99) & $357.17(333.42-380.91)$ & $-7.17(-51.88-37.55)$ & 0.854 \\
\hline \multirow{4}{*}{ Flow $_{\mathrm{ex}}\left(\mathrm{cm}^{3} / \mathrm{s}\right)$} & \multirow{2}{*}{ Deviated } & Before & $296.87(267.61-326.12)$ & $363.77(347.18-380.35)$ & $66.90(36.10-97.70)$ & 0.003 \\
\hline & & After & $355.53(330.27-380.80)$ & $358.20(346.16-370.24)$ & $2.67(-24.75-30.08)$ & 0.787 \\
\hline & \multirow{2}{*}{ Non-deviated } & Before & $347.93(338.03-357.83)$ & 371.50 (341.70-401.30) & $23.57(-13.07-60.20)$ & 0.673 \\
\hline & & After & $394.30(355.00-433.60)$ & $383.93(353.86-414.01)$ & $-10.37(-63.16-42.43)$ & 0.880 \\
\hline \multirow{4}{*}{ tFlow $\left(\mathrm{cm}^{3} / \mathrm{s}\right)$} & \multirow{2}{*}{ Deviated } & Before & $566.57(507.84-625.30)$ & $708.70(677.52-739.88)$ & $142.13(79.51-204.76)$ & 0.001 \\
\hline & & After & $674.20(629.56-718.84)$ & $698.83(677.91-719.75)$ & $24.63(-24.25-73.52)$ & 0.309 \\
\hline & \multirow{2}{*}{ Non-deviated } & Before & $677.37(660.36-694.37)$ & $719.73(665.85-773.62)$ & $42.37(-22.05-106.79)$ & 0.666 \\
\hline & & After & $758.63(686.54-830.73)$ & 741.10 (687.42-794.79) & $-17.53(-114.34-79.27)$ & 0.948 \\
\hline \multirow{2}{*}{ TFlow $\left(\mathrm{cm}^{3} / \mathrm{s}\right)$} & & Before & $1243.93(1182.18-1305.69)$ & $1428.43(1350.71-1506.16)$ & $184.50(89.30-279.70)$ & 0.001 \\
\hline & & After & $1432.83(1343.25-1522.42)$ & $1439.93(1372.74-1507.12)$ & $7.10(-103.32-117.52)$ & 0.116 \\
\hline \multirow{4}{*}{$\mathrm{AR}_{\text {ins }}\left(150 \mathrm{~Pa} / \mathrm{cm}^{3} / \mathrm{s}\right)$} & \multirow{2}{*}{ Deviated } & Before & $0.685(0.529-0.840)$ & $0.440(0.425-0.455)$ & $-0.245(-0.400--0.089)$ & $<0.001$ \\
\hline & & After & $0.496(0.445-0.546)$ & $0.442(0.432-0.453)$ & $-0.053(-0.105--0.001)$ & 0.048 \\
\hline & \multirow{2}{*}{ Non-deviated } & Before & $0.457(0.447-0.467)$ & $0.442(0.421-0.462)$ & $-0.016(-0.042--0.011)$ & 0.649 \\
\hline & & After & $0.432(0.402-0.462)$ & $0.431(0.410-0.452)$ & $-0.002(-0.042-0.039)$ & 0.787 \\
\hline \multirow{4}{*}{$\mathrm{AR}_{\mathrm{ex}}\left(150 \mathrm{~Pa} / \mathrm{cm}^{3} / \mathrm{s}\right)$} & \multirow{2}{*}{ Deviated } & Before & $0.579(0.477-0.682)$ & $0.417(0.403-0.432)$ & $-0.162(-0.263--0.061)$ & 0.002 \\
\hline & & After & $0.437(0.408-0.467)$ & $0.422(0.410-0.433)$ & $-0.016(-0.047-0.016)$ & 0.658 \\
\hline & \multirow{2}{*}{ Non-deviated } & Before & $0.434(0.421-0.448)$ & $0.416(0.396-0.436)$ & $-0.018(-0.049-0.013)$ & 0.704 \\
\hline & & After & $0.402(0.373-0.431)$ & $0.404(0.382-0.426)$ & $0.002(-0.037-0.041)$ & 0.957 \\
\hline \multirow{4}{*}{$\operatorname{tAR}\left(150 \mathrm{~Pa} / \mathrm{cm}^{3} / \mathrm{s}\right)$} & \multirow{2}{*}{ Deviated } & Before & $0.309(0.249-0.369)$ & $0.214(0.207-0.221)$ & $-0.095(-0.155--0.036)$ & 0.001 \\
\hline & & After & $0.231(0.213-0.249)$ & $0.216(0.211-0.221)$ & $-0.015(-0.034-0.003)$ & 0.284 \\
\hline & \multirow{2}{*}{ Non-deviated } & Before & $0.223(0.217-0.228)$ & $0.214(0.204-0.224)$ & $-0.008(-0.022-0.006)$ & 0.688 \\
\hline & & After & $0.208(0.193-0.223)$ & $0.208(0.198-0.219)$ & $0.000(-0.019-0.020)$ & 0.905 \\
\hline \multirow{2}{*}{$\operatorname{TAR}\left(150 \mathrm{~Pa} / \mathrm{cm}^{3} / \mathrm{s}\right)$} & & Before & $0.123(0.116-0.131)$ & $0.107(0.103-0.111)$ & $-0.017(-0.025--0.009)$ & 0.001 \\
\hline & & After & $0.107(0.102-0.113)$ & $0.106(0.102-0.109)$ & $-0.002(-0.008-0.005)$ & 0.116 \\
\hline
\end{tabular}

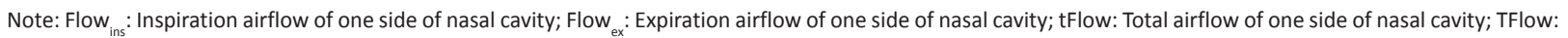
Total airflow of two sides of nasal cavity; $\mathrm{AR}_{\mathrm{ins}}$ : Inspiration airway resistance of one side of nasal cavity; $\mathrm{AR}_{\mathrm{ex}}$ : Expiration airway resistance of one side of nasal cavity; tAR: Total airway resistance of one side of nasal cavity; TAR: Total airway resistance of two sides of nasal cavity.

*Related-Samples Wilcoxon Signed Rank Test was used.

preoperative and postoperative NOSE score was 60.50 and 7.33 , respectively, with a mean difference of 53.17 points. This difference was found to be statistically significant.

In a study, it was reported that an improvement in NOSE score of approximately $40 \%$ or higher was required to define the surgery as successful (22). Also, changes in NOSE scores after surgery were evaluated in a systematic review and metaanalysis, and the mean improvement was found as 50.0 points at the early evaluation (12). Stewart et al. demonstrated a 31 to 37 points change in NOSE score in their original septoplasty study (23). In our study, all patients had improvements of more than 30 points in NOSE scores, except two patients with improvement scores of less than 30 points.
$A R$ and AAR measurements have been performed after decongestion of the nose with a topical decongestant in the studies that investigated the effectiveness of the septoplasty $(6,11,21)$. The use of nasal decongestants eliminates vascular causes of nasal obstruction and provides a more appropriate evaluation chance for the hard tissue components of nasal obstruction (6). In our study, we measured all parameters $B D$ and $A D$ and took part in $A R$ and $A A R$ measures. We have demonstrated a comparison of preoperative and postoperative results in Tables 3 and 4 and exhibited the statistically significant correlations between the differences in objective measurements and the differences in NOSE scores of the patients. In our study, we found statistically 
Table 5: Statistically significant correlations between anatomical measurements, differences in functional measurements and differences in NOSE scores

\begin{tabular}{|c|c|c|c|c|}
\hline & & \multicolumn{3}{|c|}{ Difference in NOSE score } \\
\hline & & $\mathbf{R}$ & $\mathbf{n}$ & $p^{*}$ \\
\hline \multirow{3}{*}{ Anatomical measurements } & CW (DS) & 0.429 & 30 & 0.018 \\
\hline & CW (NDS) & 0.514 & 30 & 0.004 \\
\hline & UPW & 0.397 & 30 & 0.030 \\
\hline \multirow{12}{*}{ Difference in functional measurements } & Vol2 $\left(\mathrm{cm}^{3}\right)$ (NDS/BD) & -0.377 & 30 & 0.040 \\
\hline & tVol1 $\left(\mathrm{cm}^{3}\right)$ (NDS/BD) & -0.401 & 30 & 0.028 \\
\hline & TVol1 $\left(\mathrm{cm}^{3}\right)(B D)$ & -0.372 & 30 & 0.043 \\
\hline & Flow $_{\text {ins }}\left(\mathrm{cm}^{3} / \mathrm{s}\right)(\mathrm{DS} / \mathrm{AD})$ & -0.409 & 30 & 0.025 \\
\hline & Flow $_{\text {ex }}\left(\mathrm{cm}^{3} / \mathrm{s}\right)(\mathrm{NDS} / A D)$ & 0.367 & 30 & 0.046 \\
\hline & tFlow $\left(\mathrm{cm}^{3} / \mathrm{s}\right)(\mathrm{DS} / \mathrm{AD})$ & -0.396 & 30 & 0.030 \\
\hline & tFlow $\left(\mathrm{cm}^{3} / \mathrm{s}\right)(\mathrm{NDS} / \mathrm{AD})$ & 0.365 & 30 & 0.047 \\
\hline & $\mathrm{AR}_{\text {ins }}\left(150 \mathrm{~Pa} / \mathrm{cm}^{3} / \mathrm{s}\right)(\mathrm{DS} / \mathrm{AD})$ & 0.418 & 30 & 0.022 \\
\hline & $\mathrm{AR}_{\mathrm{ex}}\left(150 \mathrm{~Pa} / \mathrm{cm}^{3} / \mathrm{s}\right)(\mathrm{DS} / \mathrm{BD})$ & 0.366 & 30 & 0.047 \\
\hline & $\mathrm{AR}_{\mathrm{ex}}\left(150 \mathrm{~Pa} / \mathrm{cm}^{3} / \mathrm{s}\right)(\mathrm{DS} / \mathrm{AD})$ & 0.412 & 30 & 0.024 \\
\hline & $\mathrm{AR}_{\mathrm{ex}}\left(150 \mathrm{~Pa} / \mathrm{cm}^{3} / \mathrm{s}\right)(\mathrm{NDS} / \mathrm{AD})$ & -0.368 & 30 & 0.045 \\
\hline & tAR $\left(150 \mathrm{~Pa} / \mathrm{cm}^{3} / \mathrm{s}\right)(\mathrm{DS} / \mathrm{BD})$ & 0.405 & 30 & 0.026 \\
\hline
\end{tabular}

Note: CW: Choana width; UPW: Upper palate width; Vol1: Volume 1 of one side of nasal cavity; Vol2: Volume 2 of one side of nasal cavity; tVol: Total volume of one side of nasal cavity; TVol: Total volume of two sides of nasal cavity; Flow $_{\text {ins }}$ : Inspiration airflow of one side of nasal cavity; Flow ${ }_{\mathrm{ex}}$ : Expiration airflow of one side of nasal cavity; tFlow: Total airflow of one side of nasal cavity; $A R_{\text {ins }}$ : Inspiration airway resistance of one side of nasal cavity; $A R_{\text {ex }}$ : Expiration airway resistance of one side of nasal cavity; tAR: Total airway resistance of one side of nasal cavity; DS: Deviated side; NDS: Non-deviated side; BD: Before decongestion; AD: After decongestion.

* Spearman's rank-order correlation was used.

significant differences between all pre and postoperative acoustic rhinometry variables (Except for the MCA2 of NDS) of DS and NDS of the nose both before and after decongestion. We also found significant improvements in all postoperative airflow and airway resistance parameters of DS of the nose before decongestion, when compared to the preoperative measurements.

Although AR provides detailed information about the geometry of nasal structures, it does not provide any information about the flow field and physiology of nasal pressure $(5,17)$. These parameters have critical importance because the evaluation of the physiology of the nasal airway helps surgeons to decide which patients would get better from performing a septoplasty operation (17). AAR provides detailed information about the physiology of nasal airflow and demonstrates abnormal measurements in nasal airflow and nasal pressure. Also, studies have reported that patients with severe anatomic deviation may have mild symptoms, whereas other patients with a small septal deviation have significant nasal obstruction symptoms (1). It is thought that these characteristics of AAR complete the missing parts of other objective measurements such as morphometric variables and AR measures (24).

Lara-Sanches et al. reported that performed surgery resulted in statistically significant differences with the NOSE score and
AAR measures. They did not, however, observe any correlation between the NOSE score and AAR, and concluded that the objective and subjective measurements complete each other and provide useful information from a different point of view (25). Currently, the correlation between the subjective evaluation scores and detailed objective measurements is still debated. Several studies showed correlation, whereas others did not $(2,5,17,26)$. It was pointed out that the correlation between NOSE score and objective evaluations could be affected by study design, such as having a small sample size, non-homogenous groups, or the surgical techniques performed $(12,27)$. Jones et al. observed no correlation between the objective nasal resistance measurements and subjective measures (28).

It has been stated in the literature that the lack of correlation between the objective and subjective measurements related to nasal function may be due to surgeons focusing on the nasal passage of the deviated side and ignoring the fact that the nose has two separate nasal passages (5). In a study, a significant nasal airflow increase was observed on the deviated side, but a significant airflow decrease was not observed on the nondeviated (wide side) part (29). In another study, during followup measurements, a significant increase in nasal resistance was observed in the non-deviated nasal cavity in 23 of 30 
patients with nasal obstruction (30). In the presented study, surgery significantly increased nasal airflow and reduced nasal resistance in the deviated side of the nasal septum, but did not cause any significant airflow or nasal resistance changes in the non-deviated side. It has been thought in the literature that asymmetrical nasal airflow resulting from deviated nasal septum may create spontaneous changes in the nasal cycle and that may lead to the symptoms related to nasal congestions (5).

NOSE score refers to subjective feelings about the nasal patency, AR and AAR provide additional objective detailed information on the anatomy of the nasal cavity, nasal airflow, and nasal resistance, respectively (5). In our study, we performed both objective measurements in all patients and investigated the existence of a correlation between NOSE score, AR, and AAR measurements. We then demonstrated significant correlations between the NOSE score and lots of AR and AAR parameters.

There are several limitations in the presented study. First, we could have studied a relatively smaller group of patients. Also, we did not include a control group. Another limitation of our study was the short follow-up time because several studies have reported that the improvement in symptoms and subjective evaluations at early stages decreased at the long term observation (31). In the presented study, the control measures of patients were performed at the end of the first month and therefore, we cannot comment on the long-term consequences of the surgery.

\section{CONCLUSION}

Many different follow-up and evaluation methods have been proposed to evaluate the effectiveness of the performed operations in septoplasty surgery. Some of them include subjective measurements and others include objective measurements. We performed both methods in the presented study, and then investigated the correlation of these tests. We showed that objective measurements correlate strongly with the subjective one, and further studies should be conducted to evaluate positive or negative preoperative predictors of surgical outcomes.

Ethics Committee Approval: Ethical approval was obtained from Izmir Tepecik Training and Research Hospital Ethics Committee (Approval date:18/08/2016, No:22)

Informed Consent: Written informed consent was obtained from all patients included in the study after detailed information about the study was given.

Peer-Review: Externally peer-reviewed.

Author Contributions: Conception/Design of Study- A.U., E.D.; Data Acquisition- A.U., E.D.; Data Analysis/Interpretation- A.U., E.D.; Drafting Manuscript- A.U., E.D.; Critical Revision of Manuscript- A.U., E.D.; Final Approval and Accountability- A.U., E.D.

Conflict of Interest: Authors declared no conflict of interest.

Financial Disclosure: Authors declared no financial support

\section{REFERENCES}

1. Konstantinidis I, Triaridis S, Triaridis A, Karagiannidis K, Kontzoglou G. Long term results following nasal septal surgery. Focus on patients' satisfaction. Auris, Nasus, Larynx 2005;32(4):369-74.

2. Tsang CLN, Nguyen T, Sivesind T, Cervin A. Long-term patientrelated outcome measures of septoplasty: a systematic review. European archives of oto-rhino-laryngology: official journal of the European Federation of Oto-Rhino-Laryngological Societies (EUFOS): affiliated with the German Society for Oto-RhinoLaryngology - Head and Neck Surgery 2018;275(5):1039-48.

3. Sedaghat AR, Busaba NY, Cunningham MJ, Kieff DA. Clinical assessment is an accurate predictor of which patients will need septoplasty. Laryngoscope 2013;123(1):48-52.

4. Shah J, Roxbury CR, Sindwani R. Techniques in Septoplasty: Traditional Versus Endoscopic Approaches.Otolaryngol Clin North Am 2018;51(5):909-17.

5. Hsu HC, Tan CD, Chang CW, Chu CW, Chiu YC, Pan CJ, et al. Evaluation of nasal patency by visual analogue scale/nasal obstruction symptom evaluation questionnaires and anterior active rhinomanometry after septoplasty: a retrospective oneyear follow-up cohort study.Clin Otolaryngol 2017;42(1):53-9.

6. Moore M, Eccles R. Objective evidence for the efficacy of surgical management of the deviated septum as a treatment for chronic nasal obstruction: a systematic review. Clin Otolaryngol 2011;36(2):106-13.

7. Fettman N, Sanford T, Sindwani R. Surgical management of the deviated septum: techniques in septoplasty. Otolaryngol Clin North Am 2009;42(2):241-52.

8. Kim JS, Heo SJ. Questionable Effect of Crosshatching Incision in Septoplasty. Clin Exp Otorhinolaryngol 2020;13(1):47-51.

9. Most SP, Rudy SF. Septoplasty: Basic and Advanced Techniques. Facial Plast Surg Clin North Am 2017;25(2):161-9.

10. Mondina M, Marro M, Maurice S, Stoll D, de Gabory L. Assessment of nasal septoplasty using NOSE and RhinoQoL questionnaires. Eur Arch Otorhinolaryngol 2012;269(10):2189-95.

11. Sahin C. Evaluation of Patient Satisfaction After Nasal Septoplasty Operation Using Peak Nasal Inspiratory Flow and Nasal Obstruction Symptom Score Questionnaire. J Craniofac Surg 2016;27(5):128991.

12. Floyd EM, Ho S, Patel P, Rosenfeld RM, Gordin E. Systematic Review and Meta-analysis of Studies Evaluating Functional Rhinoplasty Outcomes with the NOSE Score. Otolaryngol Head Neck Surg 2017;156(5):809-15.

13. Mladina R. The role of maxillary morphology in the development of pathological septal deformities. Rhinology. 1987;25(3):199-205.

14. Aksu F GMN, Kahveci O, Cırpan S, Karabekir S. Diameters of piriform aperture and choana: An anatomic study. Dokuz Eylül Univ Sch Med J. 2013;27(1):1-6.

15. Hilberg $O$, Pedersen OF. Acoustic rhinometry: recommendations for technical specifications and standard operating procedures. Rhinol Suppl 2000;16:3-17.

16. Clement PA, Gordts F. Consensus report on acoustic rhinometry and rhinomanometry. Rhinology 2005;43(3):169-79.

17. Cantone E, Ricciardiello F, Oliva F, De Corso E, lengo M. Septoplasty: is it possible to identify potential "predictors" of surgical success? Acta Otorhinolaryngol Ital 2018;38(6):528-35. 
18. André RF, Vuyk HD, Ahmed A, Graamans K, Nolst Trenité GJ. Correlation between subjective and objective evaluation of the nasal airway. A systematic review of the highest level of evidence. Clin Otolaryngol 2009;34(6):518-25.

19. Apaydın E, İkincioğulları A, Çolak $M$, Atan D, Ensari S, Dere $\mathrm{HH}$. The Voice Performance After Septoplasty With Surgical Efficacy Demonstrated Through Acoustic Rhinometry and Rhinomanometry. J Voice 2020;34(4):649.e15-.e20.

20. Eren SB, Tugrul S, Dogan R, Ozucer B, Ozturan O. Objective and subjective evaluation of operation success in patients with nasal septal deviation based on septum type. Am J Rhinol Allergy 2014;28(4):e158-62.

21. Lodder WL, Leong SC. What are the clinically important outcome measures in the surgical management of nasal obstruction? Clin Otolaryngol 2018;43(2):567-71.

22. Ziai H, Bonaparte JP. Determining a Successful Nasal Airway Surgery: Calculation of the Patient-Centered Minimum Important Difference. Otolaryngol Head Neck Surg 2017;157(2):325-30.

23. Stewart MG, Smith TL, Weaver EM, Witsell DL, Yueh B, Hannley $M T$, et al. Outcomes after nasal septoplasty: results from the Nasal Obstruction Septoplasty Effectiveness (NOSE) study. Otolaryngol Head Neck Surg 2004;130(3):283-90.

24. Vogt K, Jalowayski AA, Althaus W, Cao C, Han D, Hasse W, et al. 4-Phase-Rhinomanometry (4PR)--basics and practice 2010. Rhinol Suppl 2010;21:1-50.
25. Lara-Sánchez H, Álvarez Nuño C, Gil-Carcedo Sañudo E, Mayo Iscar A, Vallejo Valdezate L. Assessment of nasal obstruction with rhinomanometry and subjective scales and outcomes of surgical and medical treatment. Acta Otorrinolaringol Esp 2017;68(3):14550.

26. Mengi E, Cukurova I, Yalçın Y, Yiğitbaşı OG, Karaman Y. [Evaluation of operation success in patients with nasal septal deviation with quality of life scale and objective methods]. Tr-ENT 2011;21(4):18491.

27. Gamerra M, Cantone E, Sorrentino G, De Luca R, Russo MB, De Corso $\mathrm{E}$, et al. Mathematical model for preoperative identification of obstructed nasal subsites. Acta Otorhinolaryngol Ital. 2017;37(5):410-5.

28. Jones AS, Willatt DJ, Durham LM. Nasal airflow: resistance and sensation. J Laryngol Otol 1989;103(10):909-11.

29. Pirilä T, Tikanto J. Acoustic rhinometry and rhinomanometry in the preoperative screening of septal surgery patients. Am J Rhinol Allergy 2009;23(6):605-9.

30. Haavisto LE, Sipilä Jl. Acoustic rhinometry, rhinomanometry and visual analogue scale before and after septal surgery: a prospective 10-year follow-up. Clin Otolaryngol 2013;38(1):23-9.

31. De Corso E, Bastanza G, Di Donfrancesco V, Guidi ML, Morelli Sbarra $G$, Passali GC, et al. Radiofrequency volumetric inferior turbinate reduction: long-term clinical results. Acta Otorhinolaryngol Ital 2016;36(3):199-205. 